\title{
La modernización del Estado
}

\section{L. ¿De qué Estado hablamos?}

Es diff́cil hablar de modernización del Estado si no definimos o delimitamos el ámbito de lo que aqui entendemos por Estado: ¿sus tres poderes, o nos referimos especificamente a uno de ellos?. Si bien es cierto que todo el Estado tiene que modernizarse, parecería que esta tarea se aplica primordialmente a la administración económica. Para comenzar, ya existe una fluidez o indeterminación en el mismo concepto de modernización, porque han existido varias époces de la historia que han sido llamadas "edad moderna". Para cada generación su tiempo es la edad moderna. Por lo tanto, modemización significa caminar con la historia, ser compañeros de la historia y también cambiar la historia. Esto quiere decir que la modernización es una actividad tan compleja como lo es la historia de cada país dentro del entorno mundial. Es normal que afloren diversas teorfas y posturas sobre la modernización puesto que son distintas y aun contrarias las visiones de la misma realidad histórica.

Si el término modernización presenta esta fluidez, también el concepto de Estado expresa ámbitos y poderes diferentes, que deben modemizarse y democratizarse. Por un predominio de la teorfa neo-liberal se circunscribe la modernización al quehacer económico de la administración pública. Dicho de otra manera, de momento no se pide la privatización de la Asamblea Legislativa, de la Corte Suprema de Justicia o de la fuerza armada, aunque haya quienes administran la justicia por cuenta propia. A estas esferas públicas se les aplican normas de equidad, transparencia, justicia y democracia. La modemización de los poderes legislativo, judicial y defensa nacional se traducirán siempre en el apego a dichas normas de equidad, transparencia, justicia y democracia; nos preguntamnos si estas mismas normas no debieran también ser la medida de valor de la "modemización" aplicada al gobierno, en cuanto poder ejecutivo de la gestión económica. El parámetro de eficiencia administrativa ¿no debe estar también inspirada por esas normas sociales?.¿ ¿No estamos desfigurando el concepto de moder- 
nización cuando priorizamos la privatización sobre aquellas normas de justicia y democratización

Cuando los juristas nos hablan del Estado de Derecho entendemos que se trata de una realidad en plural: todos los ciudadanos tienen un conjunto de derechos humanos, que penetran también el ámbito económico del empleo, la educación, la salud, la vivienda, la seguridad social... El Estado de Derecho significa un Estado con Deberes. El Estado de Derecho no implica sólo la igualdad formal ante la ley, que reza el anterior Plan de Desarrollo:" La igualdad ante la ley garantiza a cada ciudadano que, independientemente de su sexo, color, posición social, profesión, religión o filiación política, el Estado le va a tratar de la misma manera". Una función del Estado es practicar la igualdad real. Si se predica el control de monopolios y oligopolios para lograr una libre competencia empresarial, la misma norma debe descender hasta los ciudadanos para que exista una digna convivencia. Aplicar a las personas lo que se predica para las empresas.

Si queremos pasar de la igualdad formal (la letra de la ley) a la igualdad real es necesario estructurar un Estado social de bienestar, que haga efectivos estos derechos económico-sociales al margen del mercado. El problema no está en la letra de la ley, sino en la sociedad que no está estructurada para hacer efectivos estos derechos. Por esta razón se está cuestionando el concepto neo-liberal de la modernización. 1

"El elemento central del Estado de bienestar es la aceptación de un compromiso público creciente en la erradicación de la pobreza, el aumento del bienestar social y el logro de la igualdad. En definitiva, que el Estado de bienestar descansa en la idea de solidaridad social y que, por lo tanto, los poderes públicos deben suscitar un espíritu de solidaridad vinculado a la idea de pertenencia a una comunidad y al objetivo de que todos los miembros de la misma alcancen su estatus de ciudadanfa. El poder público debe ser utilizado para el logro de fines morales, que no pueden reducirse al egoismo. Lo garanka de este estatus de miembros plenos de la comunidad exige el reconocimiento de unos derechos económicos y sociales, que son distriburdos fuera del mercado y de acuerdo con un principio de necesidad socialmente reconocido".2

La modernización del Estado, en sus tres o cuatro poderes (integrado el poder militar), la igualdad que emana de la justicia social, la solidaridad humana, deben reflexionarse a la luz de los siete capítulos de nuestros Acuerdos de Paz, que siguen mostrando la desintegración de nuestro tejido social. (ECA. 519-520: pp.103 -151) La práctica de la modemización no debe circunscribirse a nomas impuestas desde fuera, silenciando nuestros documentos y compromisos nacionales. Si en esta misma década el informe de la Comisión de la Verdad, en su análisis de "la fenomenología de la violencia" llega a la conclusión jurf́dica de que las instituciones delinquen (ECA. 1993. 523; p.164), deducimos que el con- 
cepto y la vigencia de lo justo y de la justicia es todavía débil y fragmentado en el ámbito judicial, legislativo, de la seguridad social y también en su aplicación económica. Hay transferencias y vasos comunicantes en las conductas de todos estos poderes públicos, porque las simples amnistras no cambian por sI mismas las conciencias y los comportamientos. La modernización no puede ser algo simplemente cuantitativo de más o de menos Estado, sino de un distinto Estado moral.

Por lo tanto al Estado moderno le compete ser una institución creadora de valores, de fines morales que no pueden reducirse al egoismo, y ello precisamente cuando la mundialización abate las fronteras y las culturas nacionales. Son estos fines morales quienes deben prefigurar la reorganización modernizante del Estado en la esfera del quehacer económico a nivel de teora y de aplicación de las politicas economicas.

\section{Defínición e historia.}

La modernización del Estado significa la readecuación organizativa y de su personal administrativo a las funciones que le está demandando la cambiante historia. Es la historia nacional, regional y mundial quien determina sus funciones y responsabilidades. Un Estado modemo es el que en cada momento acompaña y camina con la nación. Sus funciones emanan de los problemas de la nacion y su principal función es conocer esta realidad problemática para proponer y concentar soluciones. La modernización es una responsabilidad dependiente de cada historia. La dificultad radica en que la historia cambia en cada pals a lo largo del tiempo y tambien son diferentes las historias en las distintas naciones y continentes. Por lo tanto no puede haber un único modelo de Estado moderno. Tampoco son los problemas económicos los únicos parámetros que determinan la extension, la identidad y la naturaleza del Estado; a lo largo del tiempo, otros factores culturales, tradicionales e incluso religiosos, han determinado la línea de sucesion, las caracteristicas y la identidad del Estado como autoridad y como creador de valores. Es diffcil imponer una etiqueta uniforme a todos los Estados.

De manera especial, uno de los principales factores que rompe la uniformidad de los Estados es el nivel de desarrollo humano-cultural de sus ciudadanos. Ello permite una mayor delegación de funciones y una apertura más amplia de los vasos comunicantes entre la administración pública y privada. Otras veces les ha correspondido a los Estados hacerse cargo de funciones no realizadas o anárquicamente ejecutadas por grupos del sector privado. En el análisis de la modernización del Estado conviene tener presente la distinción entre Gobierno y Administración Pública. A los franceses les ha gustado decir: hemos podido estar mal gobernados, pero estamos bien administrados. La distinción es importante porque los gobiernos cambian y la administración pública queda; pero si cambian los dos el problema se duplica. 
Si a lo largo del siglo ha habido dos fases de modernización estatal, en sentido contrario, la primera de ensanchamiento y ampliación de funciones (1930-1970...), la segunda de reducción y de reconversión de funciones (1970...), al terminar el milenio volvemos a entrar en una fase de evaluación, incluso de tenso debate sobre el papel y responsabilidades del Estado.(ECA, 1996. 567-568; p.62...) Por una parte, la mundialización económica y cultural "reduce los márgenes de acción de los gobiernos nacionales", y por otra parte, al interior de las naciones y de los bloques dependientes se incrementan los problemas sociales (pobreza, desempleo, marginación...), el retraso técnico junto con el deterioro ecológico, así como la pérdida de los valores éticos y humanos, al mismo tiempo que crece la preocupación por el desarrollo. A esta lista se agrega el complicado manejo de las políticas macroeconómicas. Nos hallamos en una etapa de tensión y transición, donde la modernización no es tanto un proceso cuantitativo, sino esencialmente cualitativo, del cual emerga un Estado al servicio de la nación.(Realidad, № 54,1996:p.750...)

\section{Estado y Gobiernos.}

La tesis neoliberal enuncia: el Estado es el problema. Ante esta posición unilateral hacemos la pregunta: ${ }^{\mathrm{E} E l}$ problema es el Estado o son los gobiernos? En torno a la modernización del Estado, con sus grandes funciones, poderes y responsabilidades, es posible enunciar otra tesis: con frecuencia, el mayor enemigo del Estado suelen ser los gobiernos. Estado y gobiernos son dos instituciones diferentes: el primero es singular y perenne, mientras que los segundos son plurales y transitorios. El Estado es algo perenne: sus problemas, funciones y responsabilidades vienen del largo plazo y tienen por horizonte el largo plazo. Sus funciones y responsabilidades requieren, por lo menos, una elevada cualificación profesional y una sensibilidad social. Si alguna de estas cualidades falta puede incurrirse en la formulación de promesas inalcanzables o en un tecnocratismo frío y sin corazón. Este estilo de acusaciones las hemos escuchado entre los gobiernos que entran y los que salen.

En este tren del Estado se montan, por turno, los sucesivos gobiernos y descubren, bien pronto, que cuentan con un grado de poder y con un volumen de fondos disponibles. Las funciones y las responsabilidades se insertan en los discursos públicos, porque pertenecen al largo plazo, mientras que el poder y los fondos disponibles se terminan en el más corto plazo. Estas han sido las acusaciones tradicionales contra gobiemos que prometen cambiar para mejorar, porque ni el poder, ni los erarios percibidos se corresponden con las promesas electorales. He aquí el desafío de cómo lanzar un puente entre la perennidad del Estado y la transitoriedad de los gobiernos.

Uno de los puentes sería el equipo de técnicos actualizados y más permanentes, que debieran mantener las instituciones públicas, sin peligro de 
desmenbramiento a cada vaivén político. Estos equipos técnicos son los conocedores y transmisores de la "tradición económica", entendida como la trayectoria de los problemas y desafíos nacionales, que la historia anterior hereda a la presente. Esta relativa permanencia no se asegura si no hay una previa seleción profesionalmente meritoria y no partidista, si los equipos técnicos nacionales no son equitativamente remunerados, si son sometidos a la veleidad e incompetencia de las jefaturas políticas o, como parece suceder, quedan supeditados al arbitrio de asesores externos de moda, quienes a veces dan la impresión de ser inteligencias-golondrinas, bastante costosas, en busca de un nido donde incubar experimentos económicos. La administración pública necesita de profesionales tanto o más cualificados que la administración privada. Es preocupante que muchos de estos profesionales emigren al sector privado: por culpa de algunos gobiemos, el Estado se ve así privado de la requerida base técnica. A este propósito recomendamos el conciso y agudo artículo del Ing. Héctor Dada:" ¿La dictadura del "empresariadao"? (Co-Latino;7-02-97; p.15), que aparecerá próximamente integrado en otro artf́culo:" ¿Es ético canonizar la globalización?". (ECA. mayo 1997).

Otro puente fundamental entre lo perenne y lo transitorio, entre lo estructural y lo coyuntural, son los planes de desarrollo. Mientras el sector privado actualiza su planificación estratégica, los gobiernos se dispensan de esta tarea a nivel nacional. Los planes de desarrollo son especialmente necesarios para los países en desarrollo, máxime cuando nos abate la desintegración social y económica. Los parses desarrollados crearon sus planes de desarrollo en las décadas difíciles de reconstrucción, recuperación y reintegración de sus economías nacionales. Los planes de desarrollo no son cuestión de moda, sino de necesidad. Estos planes tienen dos virtualidades: permiten entablar una economfa concertada entre las instituciones de la administración pública y los representantes de los sectores privados. A ello sirven las nuevas técnicas de la contabilidad nacional. Los planes de desarrollo también sirven para que los gobiernos conozcan y actualicen sus funciones. Sin un plan de desarrollo el gobierno no se conoce a sf mismo, ni los problemas nacionales, ni los ciudadanos conocemos qué quiere el gobierno. Sin un plan de desarrollo sólo queda la improvisación.

\section{Estado y Privatización.}

Ahora se extiende el clamor de la privatización, de parte de un sector relativamente minoritario, basados en la tesis de que el Estado es un mal administrador. Literalmente, ANEP ha dicho: "El sector público tiende a manejar poco eficientemente los recursos y es miope para conocer a ciencia cierta las necesidades particulares de los ciudadanos; por ello, debe regresar a su lugar y tomar el rol subsidiario que le corresponde, abriendo paso a las iniciativas de la sociedad civil, para que ésta, on conocimiento de sus verdaderas necesidades, y armada de una dosis de solidaridad, asuma su rol protagónico". (p.16) Esta 
declaración deja flotando en el aire algunas preguntas. La sociedad civil, a que se refiere ANEP, ¿da muestras de estar anmada de una dosis de solidaridad? ¿Da muestras de conocer y de responder a las verdaderas necesidades de toda la sociedad?- La sociedad civil, a que se refiere ANEP ¿está manejando eficientemente sus recursos y cumple su rol protagónico empresarial? ¿Por que salir oficialmente a solicitar la venida de la inversión extranjera? Si el sector público es tan miope y tan poco eficiente ¿por que encomendarle la función de subsidiaridad de las grandes necesidades de la mayorfa de la población?- No hay mucha logica ni gran solidaridad con esta función de la subsidiaridad.

Los sectores que reclaman la privatización de servicios y empresas públicas utilizan un argumento que no lo aplican a la empresa privada. Si una mediana o gran empresa es ineficiente por estar mal administrada se procede al cambio de los gerentes o administradores, pero los accionistas siguen siendo los dueños de la empresa. En las empresas públicas el dueño es el Estado y los accionistas son la Nación. Por añadidura, en los países donde la estructura fiscal es regresiva, el financiamiento de estas empresas recae relativamente más en los sectores de menores ingresos, y relativamente menos en los de mayores ingresos. Por lo tanto, las decisiones sobre el modo de llevar a cabo las privatizaciones no puede legislarse sin tomar en cuenta a los accionistas mayoritarios.

Además, la privatizacón se debe concentrar en las alternativas para mejorar la administración eficiente de los servicios públicos, y no en la confiscación de una propiedad que es nacional. Debe mantenerse la propiedad estatal para garantizar y controlar que la administración de los servicios públicos sea social, es decir para todos. Si al Estado se le priva de la escasa propiedad pública nacional, se anula de raíz la posibilidad de garantizar y controlar la administración privada, nacional o extranjera, de servicios que deben siempre ser públicos. Al confiscar la propiedad del Estado se le priva de toda capacidad de ejercer su función de subsidiaridad en servicios tan básicos como los que se ha legislado privatizar. Al Estado no le quedará más remedío que someterse a las fuerzas del mercado nacional e internacional. Con las privatizaciones reclamadas por los grupos de poder se le reduce al Estado incluso la función de subsidiaridad que previamente le habían delegado. Con la privatización de servicios públicos rentables, o con capacidad de posible rentabilidad, se arriesgan seriamente los equilibrios fiscales del futuro con el espejismo de los elevados ingresos presentes: se pone en serio peligro la requerida inversión social. El gobierno presente traspasa el problema a la Nación futura.

Por el hecho mismo de tratarse de empresas y servicios públicos se hace imprescindible la modemización de su administración por un doble motivo: en cuanto empresas de elevados presupuestos, generadoras de deuda externa, deben gerenciarse de acuerdo a las modernas directrices de administración empresarial, sea que trabajen con presupuestos equilibrados, con déficit o con superavit. El 
corecter social de las empresas públicas no nace de su modo de propiedad, sino de su administración éticamente sana y económicamente eficiente. Existe un consenso generalizado de que en algunas instituciones públicas ha proliferado la comupción junto con la ineficiencia administrativa. La imporancia de algunas instituciones públicas parece ser función directa del número de ministerios y jefaturas que avalan o vetan sus decisiones. Con ello los proyectos se complican, se retrasan y la deuda externa crece. En resumen, recogemos esa doble situación que siente el paciente ciudadano ante ciertas instituciones públicas: el sacrificio del "tiempo de espera" y la tiranía del empleado subalterno que nos dice: vuelva usted mañana. Repetimos la pregunta: ¿el problema es el Estado o son los gobiemos?.

Reconocemos as! algunos serios defectos de ciertas administraciones públicas, que dan pie al proceso de privatización. Pero hay lugar de recordar un antiguo principio del derecho romano: "abusus non tollit usum": el abuso no priva del derecho al uso. Es decir, que el deber de los gobiemos es cortar los abusos y no renunciar al uso, si ello es necesario para el mayor bien común. Es triste, por no decir ilogico, que los gobiernos nacionales se presenten como fervientes defensores de la privatización de muchos servicios públicos, porque eso equivale a confesarse incompetentes para corregir los abusos, para administrar los bienes de la nación, luego de todas las promesas verbales y escritas vertidas en la fase preelectoral. Adicionalmente, toda la avalancha de privatizaciones anunciadas para 1997 (ANTEL, CEL, puertos, aeropuertos, pensiones y seguridad social...) se están gestionando con un oscuro "sigilo" y falta de transparencia o diálogo, que nos hace temer una protesta social al momento de su aprobación por el poder legislativo. También en la esfera de las privatizaciones nos da la impresión de éste es el gobierno del diálogo, que no escucha a nadie; aunque sI se tiene idea de a quiénes escucha.

\section{Las sociedades prósperas son las que existen en función del ser humano.}

Este era el logotipo de la Cumbre Mundial sobre el Desarrollo Social, en 1995. Los documentos de antecedentes mostraban tres grandes problemas mundiales: se generaliza la pobreza, el crecimiento con desempleo y la atomización o insolidaridad social. Este logotipo enfrenta a los Estados con tres problemas: el humano de la pobreza, el económico del desempleo y el social de la insolidaridad, es decir, el antidesarrollo de las naciones. Es claro que este logotipo no coincide con otros conceptos de modemización, concretamente con los aplicados a la restriccción del espacio y funciones públicas, a la privatización de sus activos, a la sola función de subsidiaridad estatal, a la simple tecnificación de la administración pública y a la reducción de sus puestos de trabajo. Por supuesto que también hay que dar tiempo a estos problemas, por ser tan importantes.

Es claro que el logotipo de la Cumbre Mundial no encaja con los principios 
modernizantes del neoliberalismo imperante, porque el dearsollo de los seres humanos es un futuro, un dearsollo escatológico al final de los tiempos, que brotara de la sumatoria del desigual crecimiento individual presente. Para el neoliberalismo las sociedades prósperes se miden por el crecimiento de otras variables macro-financieras, tal como tratan de ensefiar nuestras instituciones gubernamentales. (ECA: 1996.567-568; pp.67-72)

El logotipo de Copenhague nos centra en el eje de la modernización. El ser humano es lo más moderno que existe, precisamente porque es lo más antiguo. El ser humano siempre ha sido moderno o moderno a medias, porque el ser humano siempre ha estado presente, pero ni antes ni ahora ha sido tratado, por lo general, como ser humano. Este ha sido el problema siempre moderno en la historia de la humanidad. No inventemos otra modernización. Ahora lo redescubrimos al enfatizar el desarrollo del capital humono, a condición de no pervertir esta expresión, haciendo del hombre una nueva servidumbre de la revolución tecnológica.

Vale la pena recordar que el plan de desarrollo económico y social, 1989-1994, del primer gobiemo-ARENA, siempre bajo el lema de la función subsidiaria del Estado, relegaba al mismo Estado la responsabilidad de los programas de educación, salud-nutrición, vivienda, familia, previsión social, sector laboral y la polftica ecológica. Dos cosas nos llamaban y llaman la atención todavfa. Primero, que se dijera "función subsidiaria" a la solución de los problemas más extensos y más universales de la nación. Segundo, que se marcara una abierta distinción entre los programas del desarrollo economico (primera parte del plan) y los programas del desarrollo social (segunda parte), cuando el ser humano es el principal ser económico. Ahora no tenemos un plan de desarrollo, pero podemos aplicar estas reflexiones al Presupuesto de 1997, porque sus partidas contables miden la pérdida de los valores morales.

Al mismo tiempo que la pobreza y el daempleo nos angustian porque no son variables, sino datos constantes de nuestre economfa, la insolidaridad social nos exige cada año partidas crecientes del Presupuesto nacional. La seguridad y la defensa nacional nos cuestan cada vez más caro y las leyes antidelincuenciales no logran frenar sus efectos. Tambien son elevadas las partidas conjuntas de la administración de justicia y de aquellas instituciones que fiscalizan el buen uso de los fondos públicos. Como lo señalan las investigaciones y las encuestas de opinión pública el derroche no viene de los fondos contables, sino de las malas conductas hechas costumbres; ahf se asienta el problema de la corrupción y de la ineficiencia de que incluso se acusan mútuamente algunas dependencias públicas. También desde el sector privado podemos ser cómplices de este mal, porque para que haya corrupción hacen falta dos personas: el que pide y el que acepta, el que paga y el que recibe, el que enseña y el que aprende, el que se va y el que se queda. La modernización del Estado no se logra recortando las 
partidas, sino investigando y castigando las malas costumbres que se hacen norme.

Ál leer el Presupuesto de cara a la nación, sus cifras contables nos indican que el Estado tiene una función más transcendente que la subsidiaridad. El sector privado pide que se rehaga la infraestructura física, y ello es necesario, pero la sociedad necesita aún más que se rehaga la infraestructura social: la educación ampliada, la salud nutrición, la vivienda, la seguridad social y la integración familiar... Porque para que las empresas vivan es menester que la humanidad sobreviva. También es menester que la naturaleza sobreviva; los ecologistas dicen que la naturaleza irrespetada nos devuelve el boomerang del cáncer.

Con estas reflexiones llegamos a una conclusión final: es el Estado quien debe dejarse subsidiar para poder cumplir las funciones sociales de un Estado moderno.(Realidad, 1996; N 54;p.752) Pero un Estado no puede ser forjador del desarrollo social si emerge de una sociedad, cuyos grupos de poder proponen como paradigma o modelo nacional los estilos de vida del primer mundo; ni son económicamente posibles, ni éticamente imitables. (ECA.1996. 576; p.885) Las elecciones formalmente democráticas no siempre producen los resultados más democráticos. Los conservadores neoliberales no estarán de acuerdo con todas estas reflexiones. Tampoco nosotros estamos de acuerdo con los principios neoliberales, porque las sociedades prósperas son las que existen en función del ser humano.

\section{Bibliograña.}

1. Carta de los Provinciales Latinoamericanos de la Compañ́a de Jesús: "El neoliberalismo en América Latina". Ciudad de México, 14 de noviembre 1996.

2 Ibisate F.J."Propuestas de bienestar ¿con Estado de bienestar?" ECA.N.576. Octubre 1996;pp. 868-869. 